\title{
Expansão Urbana em Unidade de Conservação de Uso Sustentável: conflitos entre a política local e o interesse regional
}

\author{
Urban Expansion in Conservation Areas of Sustainable Use: \\ Conflicts between local politics and regional interest
}

Expansión Urbana en Unidad de Conservación de Uso Sostenible:

conflictos entre la política local y el interés regional

Décio Luiz Pinheiro Pradella Mestrando em Urbanismo, POSURB, PUC Campinas, Brasil deciopradella@yahoo.com.br

\author{
Laura Machado de Mello Bueno \\ Professora Doutora, POSURB, PUC Campinas, Brasil \\ Laurabueno500@gmail.com
}




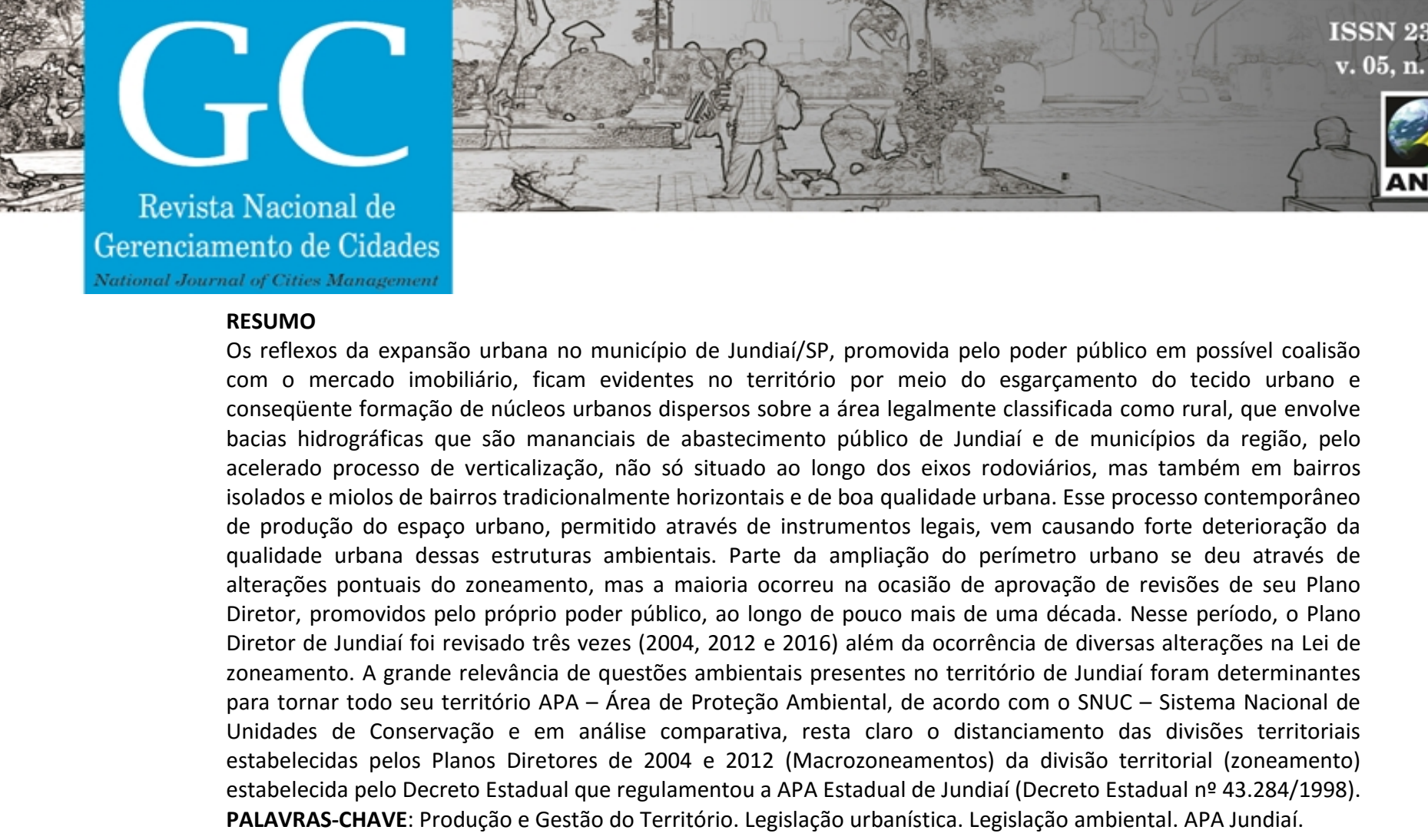

PALAVRAS-CHAVE: Produção e Gestão do Território. Legislação urbanística. Legislação ambiental. APA Jundiaí.

\section{Abstract}

The reflexes of urban expansion in the municipality of Jundiaí, promoted by public power, in a possible coalition with real estate market, are evident in the territory through the fragmentation of urban fabric and consequent formation of dispersed urban nuclei over an area legally classified as rural. These areas involve watersheds that are sources of public water supply to Jundiaí and regional municipalities, and an accelerated process of verticalization, not only along the highways, but also in isolated neighborhoods and nucleus of traditionally horizontal neighborhoods of good urban quality. This contemporary process of production of urban space, allowed through legal instruments, has been causing a strong deterioration of urban quality of these environmental structures. Part of the urban perimeter expansion occurred through occasional zoning changes, but mostly at approval of Jundiaí Municipal Master Plan revisions, promoted by the public power itself, over a little more than a decade. During this period, Jundiaí Municipal Master Plan was revised three times (2004, 2012 and 2016) in addition to the occurrence of several changes in the Zoning Law. The great relevance of environmental issues present in the territory of Jundiai were decisive in order to transform all of its territory in an EPA - Environmental Protected Area, according to the National System of Conservation Units (NSCU). In a comparative analysis, it is clear the detachment of the territorial divisions established by 2004 and 2012 Municipal Master Plans (Macrozoning) from the territorial division (Zoning) established by the State Decree that regulated Jundiaí State EPA (State Decree no 43.284/1998).

KEY WORDS: Territory Production and Management. Urban planning legislation. Jundiaí EPA.

Resumen

Los reflejos de la expansión urbana en el municipio de Jundiaí/SP, fomentado por el poder público en posible alianza con el mercado inmobiliario, son irrebatibles en el territorio por medio del estiramiento del tejido urbano y la consecuente formación de núcleos citadinos dispersos sobre el área legalmente clasificada como rural, que involucra cuencas hidrográficas que son manantiales de abastecimiento público de Jundiaí y de municipios de la región, por el acelerado proceso de verticalización, no apenas situado a lo largo de los ejes viales, sino también en barrios aislados y minicentros de barrios tradicionalmente horizontales y de notable calidad urbana. Este proceso contemporáneo de producción del espacio urbano, permitido a través de instrumentos legales, viene causando fuertes destrozos de la calidad urbana de esas estructuras ambientales. Parte de la ampliación del perímetro urbano se dio por medio de alteraciones puntuales de la zonificación, pero la mayoría ocurrió concomitantemente con la aprobación de revisiones de su Plan Director, promovidos por el propio poder público, a lo largo de más de una década. En ese período, el Plan Director de Jundiaí fue revisado en tres ocasiones (2004, 2012 y 2016 ) y además fue sometido a diversos cambios en la Ley de zonificación. La gran relevancia de cuestiones ambientales presentes en el territorio de Jundiaí fueron determinantes para transformar todo su territorio en APA - Área de Protección Ambiental, en consonancia con el SNUC - Sistema Nacional de Unidades de Conservación y en análisis comparativos, quedó evidente el alejamiento de las divisiones territoriales establecidas por los Planes Directores de 2004 y 2012 (Macrozoneamientos) de la división territorial (zonificación) establecida por el Decreto Estatal que reguló la APA Estatal de Jundiaí (Decreto Estatal no 43.284 / 1998).

PALABRAS CLAVE: Producción y Gestión del Territorio. Legislación urbanística. Legislación Ambiental. APA Jundiaí. 


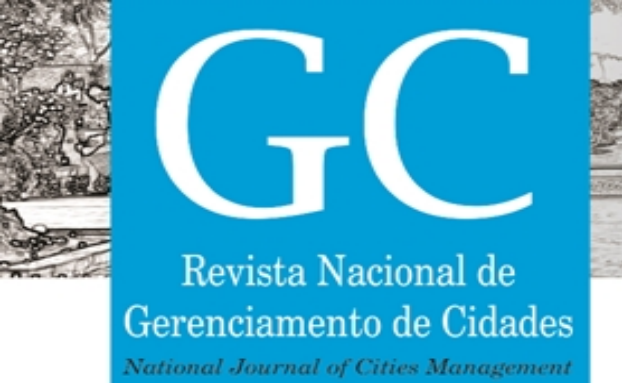

A criação de categorias diversas de Unidades de Conservação no território nacional deu-se em resposta as novas demandas da sociedade e do poder público, voltadas à preocupação crescente com a proteção do ambiente natural.

A década de 1980 foi marcada pelo início da busca do desenvolvimento sustentável, cujo conceito envolve a utilização equilibrada das espécies e dos ecossistemas de uma região, conciliado com os benefícios econômicos de interesse de sua população. O mundo inteiro, inclusive o Brasil, aumentou as possibilidades de criação de áreas protegidas. Essa preocupação se refletiu na classificação internacional das áreas protegidas publicada em 1994 pela União Internacional para a Conservação da Natureza - UICN e na legislação federal 9985/2000 que define o Sistema Nacional de Unidades de Conservação - SNUC. (ALMEIDA,1993)

Essa legislação definiu dois tipos de unidades de conservação:

- As Unidades de Proteção Integral, com usos restritos à manutenção da biodiversidade dos ecossistemas e pesquisas científicas, são de propriedade pública e tem controle de acesso: Estação Ecológica, Reserva Biológica, Parque Nacional, Monumento Natural e Refúgio da Vida Silvestre. São criadas por lei.

- As Unidades de Uso Sustentável, permitem a presença de atividades humanas, e podem abarcar terras de propriedade privada, que devem ser utilizadas conforme um plano de manejo por legislação específica: Área de Proteção Ambiental, Área de Relevante Interesse Ecológico, Floresta Nacional, Reserva Extrativista, Reserva de Fauna, Reserva de Desenvolvimento Sustentável, que devem ser criadas por lei, e a Reserva Particular do Patrimônio Natural, que deve ser proposta pelo proprietário.

\section{As Áreas de Proteção Ambiental (APAs)}

As Áreas de Proteção Ambiental já existiam na Legislação brasileira antes do SNUC. A Lei federal no 6.902, de 27 de abril de 1981, cria as APAS e as Estações Ecológicas e em seu artigo 8 e estabelece:

“O poder executivo, quando houver relevante interesse público, poderá declarar determinadas áreas do território nacional como de interesse para a proteção ambiental, a fim de assegurar o bem-estar das populações humanas e conservar ou melhorar as condições ecológicas locais."

A Lei Federal no 9.985, de 2000, no artigo 15, define a APA como uma área "em geral extensa, com certo grau de ocupação humana, dotada de atributos abióticos, bióticos, estéticos ou culturais especialmente importantes para a qualidade de vida e o bem-estar das populações humanas, e tem como objetivos básicos proteger a diversidade biológica, disciplinar o processo de ocupação e assegurar a sustentabilidade do uso dos recursos naturais."

As APAs podem ser estabelecidas em terras de domínio público e/ou privado, respeitando os limites constitucionais das propriedades particulares. Quando em domínio privado, as atividades econômicas podem ocorrer sem prejuízo dos atributos ambientais especialmente protegidos, respeitando-se a fragilidade e a importância desses recursos naturais. (HOEFFEL, 2010). 


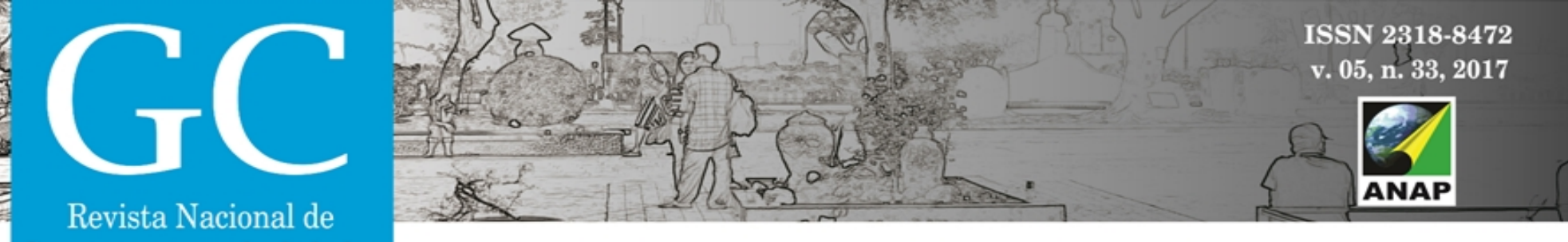
Gerenciamento de Cidades

A Lei estadual 12289/2006, incluiu na APA de Cabreúva toda a bacia do ribeirão Piraí, que tem trechos nos municípios de Cabreúva, que já era protegido como APA, Indaitauba, Itu e Salto.

A Lei estadual 12290/2006 incluiu na APA de Jundiaí toda a bacia hidrográfica do rio JundiaíMirim, ampliando a área para trechos de Jarinu e Campo Limpo Paulista, e do ribeirão Caxambu, incluindo trecho de Itupeva.

\section{Figura 2 - Zoneamento das APAs Jundiaí e Cabreúva, estabelecidos pelas Leis Estaduais 12.289/2006 e} $12.290 / 2006$

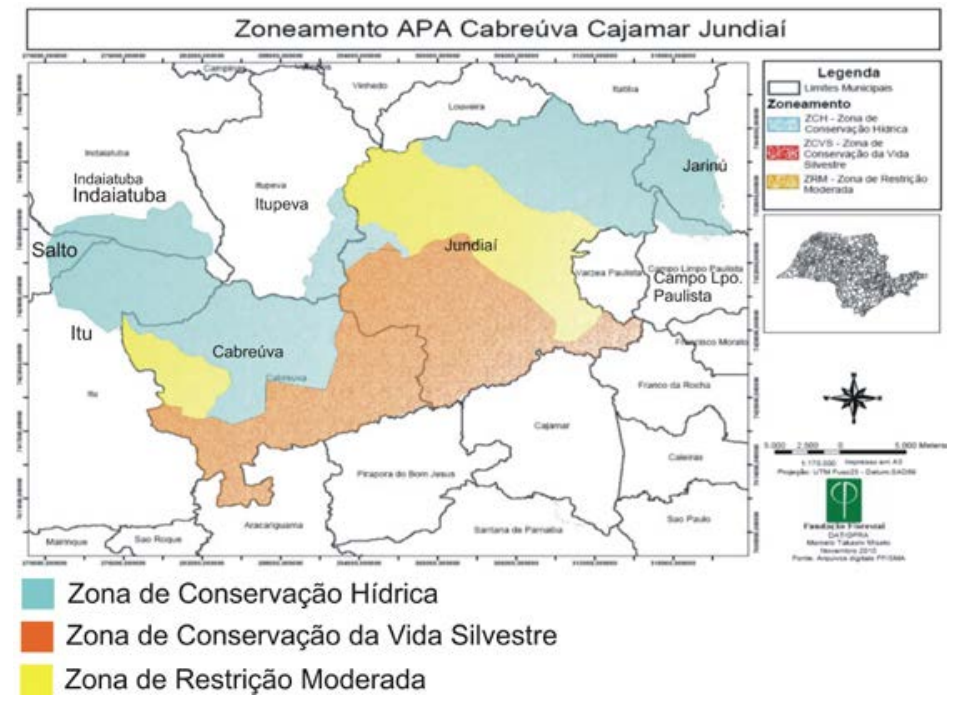

Fonte:http://www3.ambiente.sp.gov.br/fundacaoflorestal/unidades-de-conservacao/apas/

Figura 3 - Zoneamento APA Jundiaí,conforme Decreto Estadual no 43.284/98

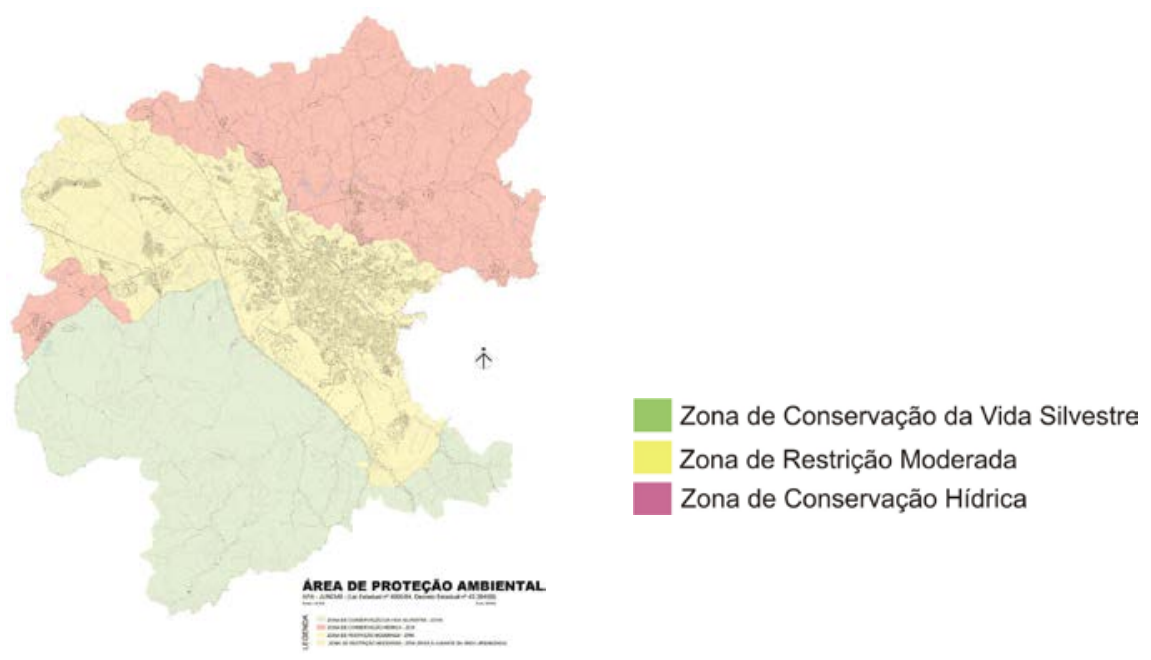

Fonte:https://www.jundiai.sp.gov.br/planejamento-e-meio-ambiente/APA_

- Zona de Conservação da Vida Silvestre (ZCVS); Destina-se à conservação da mata atlântica, da vegetação rupestre e da biota nativa, para garantir a manutenção e a reprodução das espécies e a proteção do habitat de espécies raras, endêmicas, em perigo ou ameaçadas de 


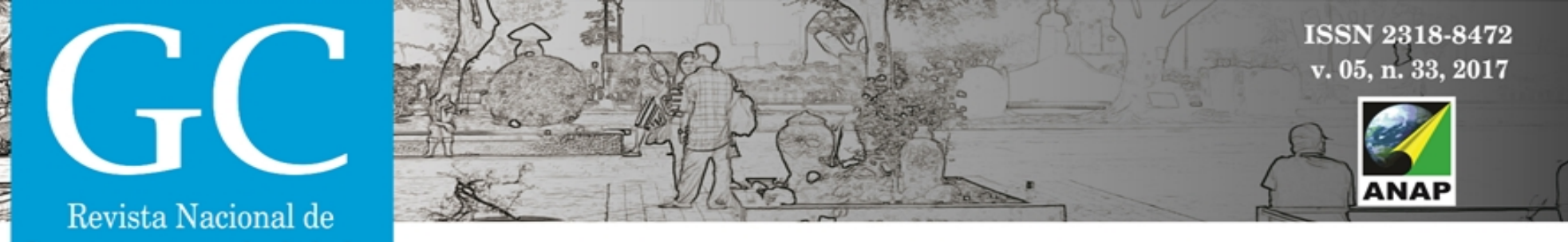
Gerenciamento de Cidades

Configura-se também como importante referência histórica, paisagística e simbólica para a população de Jundiaí. (Figura 5). Segundo Freitas e Bueno (2017), em 2015, quando foi realizada pesquisa para subsidiar a revisão do Plano Diretor, de mais de 5600 respostas, " $29 \%$ das respostas sobre o que Jundiaí tem de melhor, se concentraram na Serra do Japi, natureza, clima e água"

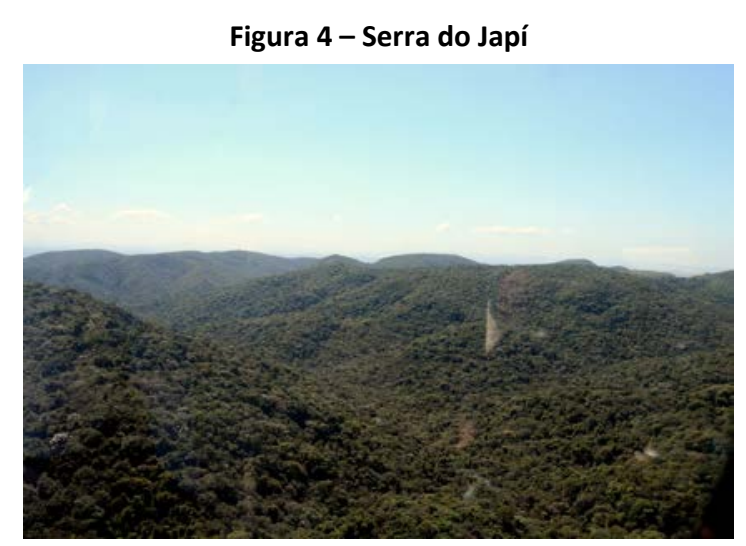

Fonte: arquivo pessoal do autor - sobrevôo 2015

A beleza cênica da Serra do Japi, assim como a qualidade ambiental proporcionada, tem atraído loteamentos e condomínios fechados de alto padrão para seu entorno, exercendo forte pressão da urbanização em sua área de amortecimento. Através de transformações pontuais do zoneamento e nos planos diretores, tem havido modificações ampliando o leque de atividades humanas, especialmente em suas bordas. É objeto de grande interesse do mercado imobiliário, principalmente em suas bordas. Há incidência de loteamentos irregulares de interesse específico em sua porção ao sul, com características de chácaras de recreio para classes médias e altas, em sua maioria.

Figura 5 - Polígono de Tombamento pelo CONDEPHAAT e Território de Gestão da Serra do Japi (Lei no 417/2004)

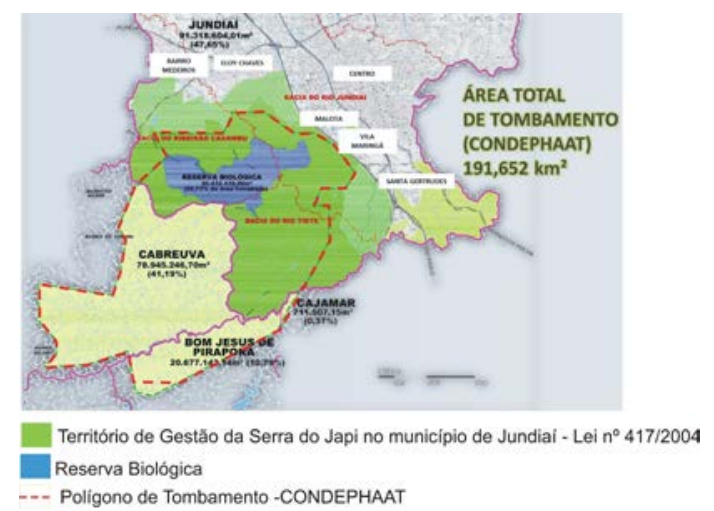

Fonte:https://www.jundiai.sp.gov.br/planejamento-e-meio-ambiente/legislacao/leis-urbanisticas/ 



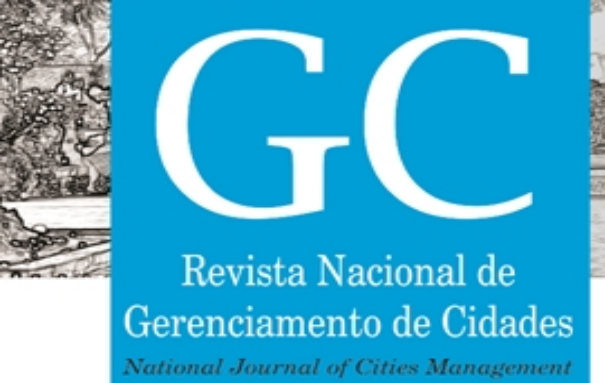

de diversos loteamentos irregulares de interesse específico, com características de chácaras de recreio em sua maioria.

\section{Ribeirão Caxambu}

A bacia Ribeirão Caxambu tem uma importância regional na questão do abastecimento público. Abrange área parcialmente situada nos municípios de Jundiaí e Itupeva. no território de Jundiaí estão os seus afluentes, os ribeirões da Cachoeira, das Pedras e da Ermida. O canal do Rio Caxambu se configura como divisa entre os municípios de Jundiaí e Itupeva. A maior parte das nascentes do Ribeirão Caxambu está inserida no território de gestão da Serra do Japi, e classificado como Zona de Conservação de Vida Silvestre (ZCVS) pela Legislação da APA. Parte delas estão inseridas também dentro do Polígono de Tombamento pelo CONDEPHAAT () e na área da Reserva Biológica Municipal.

Os médios cursos dos afluentes do Ribeirão Caxambu ocupam áreas classificadas como Zona de Conservação de Vida Silvestre (ZCVS) e Zona de Conservação Hídrica (ZCH) pela legislação da APA de Jundiaí, estando o seu baixo curso localizado em área classificada como Zona de Conservação Hídrica (ZCH) pela lei da APA de Jundiaí.

O Ribeirão Caxambu se configura como a principal alternativa de abastecimento público de Jundiaí, tendo importância fundamental também no sistema de abastecimento público do município de Itupeva. Apesar disso, sua bacia vem tendo sua característica original alterada pela presença de empreendimentos imobiliários que vem provocando considerável adensamento populacional e construtivo.

\section{Expansão do Perímetro urbano: análise comparativa entre os Planos Diretores aprovados de} 2.004 e 2.012 .

Em uma análise comparativa entre os Macrozoneamentos definidos nos Planos Diretores propostos e aprovados pela municipalidade, nos anos de 2.004 e 2.012, é possível verificar grande redução da área rural do município nesse intervalo, denominada como Macrozona Rural. Consequentemente houve grande avanço do perímetro urbano sobre essa área historicamente classificada como Zona Rural e que acomoda as propriedades agrícolas mais produtivas do município de Jundiaí e as mais importantes bacias hidrográficas de mananciais de abastecimento público de Jundiaí e região (bacias dos rios Jundiaí-Mirim, Capivari e Caxambú). Trata-se portanto de conflito com os objetivos da legislação estadual, que a classifica como ZCH - Zona de Conservação Hídrica. 



\section{Conflitos entre a legislação da APA Estadual e o Plano Diretor de Jundiaí:}

Essa expansão urbana sobre área rural e de produção de água, nesse período de apenas oito anos, fica mais evidente quando comparados os Macrozoneamentos definidos nos dois Planos Diretores citados com o Zoneamento definido pela Lei da APA - Área de Proteção Ambiental. (Figuras 2 e 3). Resta claro o progressivo distanciamento ao longo desse período, da legislação municipal com a legislação estadual da APA Jundiaí.

Preocupante, quando considerarmos que todo o território do município de Jundiaí foi considerado APA Estadual visando à proteção da Serra do japi e a proteção de áreas que abrigam mananciais de abastecimento público local e regional.

Essa expansão urbana sobre as áreas rurais, de proteção ambiental e de mananciais de abastecimento público, classificadas como Zona de Conservação Hídrica pela lei da APA Estadual, demonstra um grande conflito entre o que preconiza o Plano Diretor e a Lei Estadual da APA. Esse conflito pode ser claramente evidenciado nas propostas de usos urbanos para essas áreas, pelo Plano Diretor, apesar das restrições impostas pela legislação ambiental estadual vigente: loteamentos fechados e condomínios de casas destinados a classe alta e média alta são empreendimentos que predominam, embora também ocorram empreendimentos comerciais e de serviços.

Enfim, são usos econômicos diversos, inadequados para essas áreas ambientalmente frágeis e protegidas por lei vem sendo implantados, causando impactos mais diversos, socioambientais e culturais.

\section{CONCLUSÃO}

Observa-se que apesar da APA Estadual Jundiaí ter sido criada com o intuito de conservar essas áreas produtoras de água, de importância local e regional e promover a qualidade de vida da população, talvez seu maior desafio seja ser respeitada e considerada como referência para a realização de leis municipais, se impondo como hierarquicamente mais importante, considerando seu caráter regional, vinculada ao Sistema Nacional de Unidades de Conservação e principalmente por ter sido elaborada levando-se em consideração a importância do território municipal no que se refere às questões ambientais e seu interesse público na conservação. O progressivo avanço do perímetro urbano sobre as áreas de proteção ambiental, contrariando não apenas o que preconiza a legislação estadual, mas também as próprias características físicas do território, pode caracterizar uma coalisão entre o poder público e o mercado imobiliário, no processo de planejamento do território do município. 
